\title{
Systematic comparison of conventional oesophageal manometry with oesophageal motility while eating bread
}

\author{
P J Howard, L Maher, A Pryde, R C Heading
}

\begin{abstract}
Conventional oesophageal manometry is seldom accompanied by symptoms and may indeed be normal in patients with a history of dysphagia. We have recently shown that oesophageal manometry during eating may be helpful in the evaluation of patients with dysphagia but there has been little systematic comparison of fed oesophageal motor patterns with conventional clinical manometry. Oesophageal manometry in response to water swallows and during eating was therefore examined in 58 consecutive patients who had been referred for clinical oesophageal function studies. The patients were divided into three groups according to the percentage of peristaltic activity during conventional manometry: group $1(n=21)$ had $100 \%$ peristalsis; group $2(n=29)$ had $1-99 \%$ peristalsis and group $3(n=8)$ were aperistaltic. All the patients in group 3 had achalasia and remained aperistaltic during eating. The percentage of peristaltic activity during eating, however, was less than with water swallows in both group 1 (53\% compared with $100 \%$ ) and group $2(49 \%$ compared with $82 \cdot 3 \%$ ) patients. Synchronous contractions and non-conducted swallows were correspondingly increased during eating. Although there was a significant correlation between the amplitude of peristaltic contractions with water and bread in groups 1 and 2 , mean peristaltic amplitudes were less with bread than with water swallows. The data show that there are substantial differences in the distal oesophageal motility patterns produced by water swallows and by eating. Conventional manometry with water swallows does not allow prediction of the fed oesophageal motility pattern, except in patients with achalasia.
\end{abstract}

Normal conventional oesophageal manometry is not an infrequent finding in patients complaining of dysphagia for solids. ${ }^{12}$ We have recently shown that symptoms may sometimes be elicited by eating bread during oesophageal motility studies in patients with normal conventional manometry ${ }^{2}$ and in the present study have undertaken a systematic comparison of oesophageal motility during conventional manometry and during eating in unselected patients referred for oesophageal function tests.

\section{Methods}

PATIENTS

The patients comprised a consecutive series who had been referred for investigation of noncardiac chest pain, heartburn, or dysphagia. They had all undergone barium radiology or endoscopy, or both, before manometry. Ambulatory 23 hour $\mathrm{pH}$ studies were performed as previously described ${ }^{2}$ using a combined glass electrode(GK 2802 C, Radiometer, Copenhagen) when clinically indicated. The upper limit of normal for total acid exposure was taken as $7 \cdot 0 \%$ of recording time. ${ }^{4}$

\section{OESOPHAGEAL MANOMETRY}

Oesophageal manometry was performed using an eight lumen Arndorfer perfusion catheter, with an external diameter of $4.5 \mathrm{~mm}$ (Arndorfer Medical Specialties, Milwaukee, USA). There were four channels ( 1 to 4 ) located at the same level with a radial separation of $90^{\circ}$. The sideports to channels $1,5,6,7$, and 8 were $5 \mathrm{~cm}$ apart. The Arndorfer catheter was connected to Elcomatic EM 750 pressure transducers. The continuous analog output from the transducers was converted to digital form by the GR800 analog-to-digital converter (Aspen Medical, Dingwall, Ross-Shire, Scotland). The recordings were displayed on a computer screen in real time. The data were also stored on disc for subsequent replay and analysis of the manometric recordings. On replay of the data it was possible to expand the recording on the computer screen to facilitate the analysis of rapid swallows. Hence, if necessary the operator could select two or three swallows at a time for study.

Manometry was performed in a semirecumbent position after the patients had fasted overnight and stopped all medication for 48 hours. The catheter was passed through the nose under topical lignocaine anaesthesia and advanced into the stomach to measure intragastric pressure. Lower oesophageal 'station pull through' pressures were estimated in relation to intragastric pressure as baseline, as previously described. ${ }^{35}$ Briefly, for each of the four channels the stations with the maximum sphincter pressures were identified from the manometric recording. The mid-respiratory pressure over three or more respiratory cycles was taken as the 
sphincter pressure for each channel. Station pull through pressure was calculated as the mean from all four channels. Oesophageal body motility was performed using three channels $5 \mathrm{~cm}$ apart in the distal oesophagus. In order to record both oesophageal body motility and sphincter relaxation simultaneously, one recording channel was positioned in the lower sphincter at the point at which the highest sphincter pressure was obtained during the station pull through procedure. Lower sphincter relaxation was regarded as incomplete if the minimum residual pressure after a swallow was more than $5 \mathrm{~mm} \mathrm{Hg}$ above intragastric baseline, ${ }^{36}$ within 10 seconds of the swallow, or up until the time of the next swallow, whichever was the shorter.

Conventional oesophageal body manometry was performed using channels $5,6,7$, and 8 . The uppermost recording channel lay in the cervical oesophagus. Swallows were identified visually and confirmed on the manometric recording by the presence of a shortlived fall in pressure (or Schlucktamung ${ }^{7}$ ) followed by a contraction in the cervical oesophagus.

Oesophageal body manometry was performed in response to 15 swallows of $5 \mathrm{ml}$ water administered by syringe at not less than 20 second intervals. The catheter was left in situ and the patients ate a slice of bread while remaining semirecumbent. Since the sites of the pressure channels were unaltered, the motility recordings were directly comparable in any given individual. Contractions recorded in all four channels and showing a continuous progression down the oesophagus were regarded as peristaltic. Contractions with a simultaneous onset in the distal three channels were defined as simultaneous. Non-conducted swallows were those that failed to produce a recordable pressure in the distal oesophageal channel, above respiratory variation (approximately $20 \mathrm{~mm} \mathrm{Hg}$ ). All the manometric recordings were performed and analysed by the same operator $(\mathrm{PJH})$. The display of the recording in real time during manometry facilitated the subsequent interpretation of the recordings.

\section{ANALYSIS OF DATA AND STATISTICS}

For the purpose of analysis, patients were divided into three groups according to the percentage of peristaltic activity seen during conventional manometry using water swallows (see below): group 1, $100 \%$ peristalsis; group 2, $1-99 \%$ peristalsis; group 3, complete aperistalsis. ${ }^{6}$ Manometric diagnoses were made according to the criteria of Benjamin et al. ${ }^{8}$

Comparisons of oesophageal body parameters between groups were made using Student's $t$ test. As the data were not normally distributed, median lower oesophageal sphincter station pull through and residual pressures were analysed using Wilcoxon's rank sum test. Correlations were performed using Pearson's regression.

\section{Results}

CLINICAL DETAILS OF PATIENTS

Manometry was performed in 58 patients who were then divided into three groups as described above. In group 1 there were 13 men and eight women with a mean (SD) age of 47.6 (13.0) years. Fifteen patients presented with heartburn, two of whom had an additional complaint of dysphagia. Ambulatory $\mathrm{pH}$ studies were performed in 20 patients and were found to be abnormal in five (the remaining patient refused $\mathrm{pH}$ monitoring). Twenty patients in group 1 underwent endoscopy. Oesophagitis was found in two patients and a further patient had a Barrett's oesophagus. All 21 patients had normal oesophageal manometry.

Group 2 consisted of 14 men and 15 women with a mean age of $49.3(13.4)$ years. The main presenting complaints were heartburn (13 patients), unexplained chest pain (10) or dysphagia (6). Abnormal gastro-oesophageal reflux was found in 12 of the 26 patients who underwent pH monitoring. (Two patients refused a pH study and it was impossible to pass the $\mathrm{pH}$ probe in one patient.) Of the 28 patients who underwent endoscopy, oesophagitis was found in five and a Barrett's oesophagus in one. Twenty one patients had normal manometry, five had non-specific motility disorders, and three had diffuse oesophageal spasm.

All eight patients in group 3 had achalasia (three men and five women with a mean (SD) age of $49 \cdot 2(17 \cdot 4)$ years). As expected, dysphagia was the main presenting complaint. Endoscopy showed no evidence of oesophagitis.

\section{OESOPHAGEAL BODY MOTILITY}

Figure 1 shows the percentages of peristaltic, synchronous, and non-conducted swallows produced in response to water and bread swallows in the three groups. The percentage of peristaltic swallows with bread was significantly less than with water in both group 1 ( $53 \%$ (SEM) $(3.6)$ and $100 \%(0)$ respectively; $\mathrm{p}<0.001)$ and group $2(48.9 \%(3 \cdot 6)$ and $82.3 \%(4 \cdot 0) ; \mathrm{p}<0.001)$. The percentages of synchronous swallows with the bread were greater than with water in group 1 $(18.7 \%(2.5)$ and $0 \% ; \mathrm{p}<0.001)$ and in group 2 $(19.6 \%(2.8)$ and $6.5 \%(1.5) ; \mathrm{p}<0.001)$. The percentage of non-conducted swallows was also greater with bread than with water swallows both in group $1(27.0 \%(3.6)$ and $0 \%, \mathrm{p}<0.001)$ and in group $2(31 \cdot 8 \%(3.0)$ and $10.7 \%(3.0) ; \mathrm{p}<0.001)$. As expected, patients with achalasia produced only synchronous contractions with occasional non-conducted swallows while eating the bread.

Figure 2 shows the amplitudes of peristaltic and synchronous contractions evoked by water and bread swallows in the three groups. The mean amplitude of peristaltic contractions was significantly less with bread in group $1(88.0 \mathrm{~mm}$ $\mathrm{Hg}(\mathrm{SEM})(7.5)$ and $100.1 \mathrm{~mm} \mathrm{Hg}(7 \cdot 7) ; \mathrm{p}<0.01)$ and group $2(89.0 \mathrm{~mm} \mathrm{Hg} \mathrm{(7.6)}$ and $106.0 \mathrm{~mm}$ $\mathrm{Hg}(9 \cdot 2) ; \mathrm{p}<0.01)$. Mean synchronous contraction amplitudes were also significantly less in response to bread compared with water in group 2 (41.4 mm Hg (3.9) and 74.4 mm Hg (11.2); $\mathrm{p}<0.01)$. In the achalasic patients the mean amplitude of synchronous contractions increased during eating, though the difference was not statistically different.

Periodic peristaltic 'stripping' waves were 


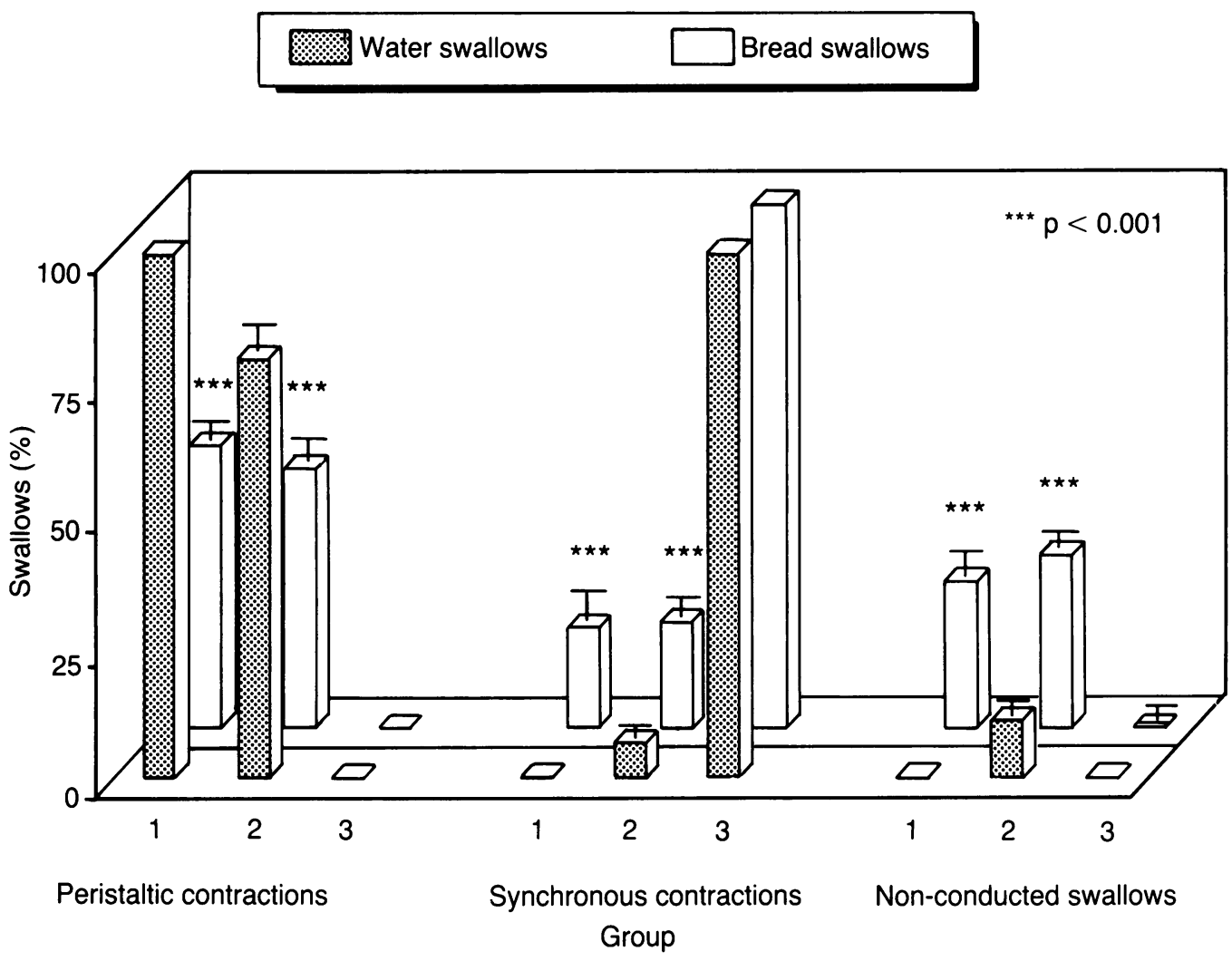

Figure 1: Percentages of peristaltic, synchronous, and non-conducted swallows in response to water and bread swallows in the three groups. Group 1 had 100\% peristalsis with water swallows $(n=21)$, group 2 had $1-99 \%$ peristalsis $(n=29)$, and group 3 had $0 \%$ peristalsis $(n=8)$

noted during eating in patients in groups 1 and 2. The maximum peristaltic amplitudes, however, were not significantly greater with bread than with water swallows in either group $1(157 \cdot 2 \mathrm{~mm}$ $\mathrm{Hg}(12 \cdot 6)$ compared with $137 \cdot 4 \mathrm{~mm} \mathrm{Hg}(10 \cdot 3)$, respectively) or group $2(160 \cdot 3 \mathrm{~mm} \mathrm{Hg}(15 \cdot 5)$ compared with $151 \cdot 1 \mathrm{~mm} \mathrm{Hg}(11 \cdot 8))$.
There were significant correlations between mean peristaltic amplitudes in response to water and bread swallows in both group $1\left(r^{2}=70 \cdot 3 \%\right.$; $\mathrm{p}<0.0001)$ and group $2\left(\mathrm{r}^{2}=54.9 \% ; \mathrm{p}<0.001\right)$ and also between maximum peristaltic amplitudes with bread and water in group $1\left(\mathrm{r}^{2}=38.5 \%\right.$; $\mathrm{p}<0.02)$ and group $2\left(\mathrm{r}^{2}=66 \cdot 1 \% ; \mathrm{p}<0 \cdot 01\right)$. There

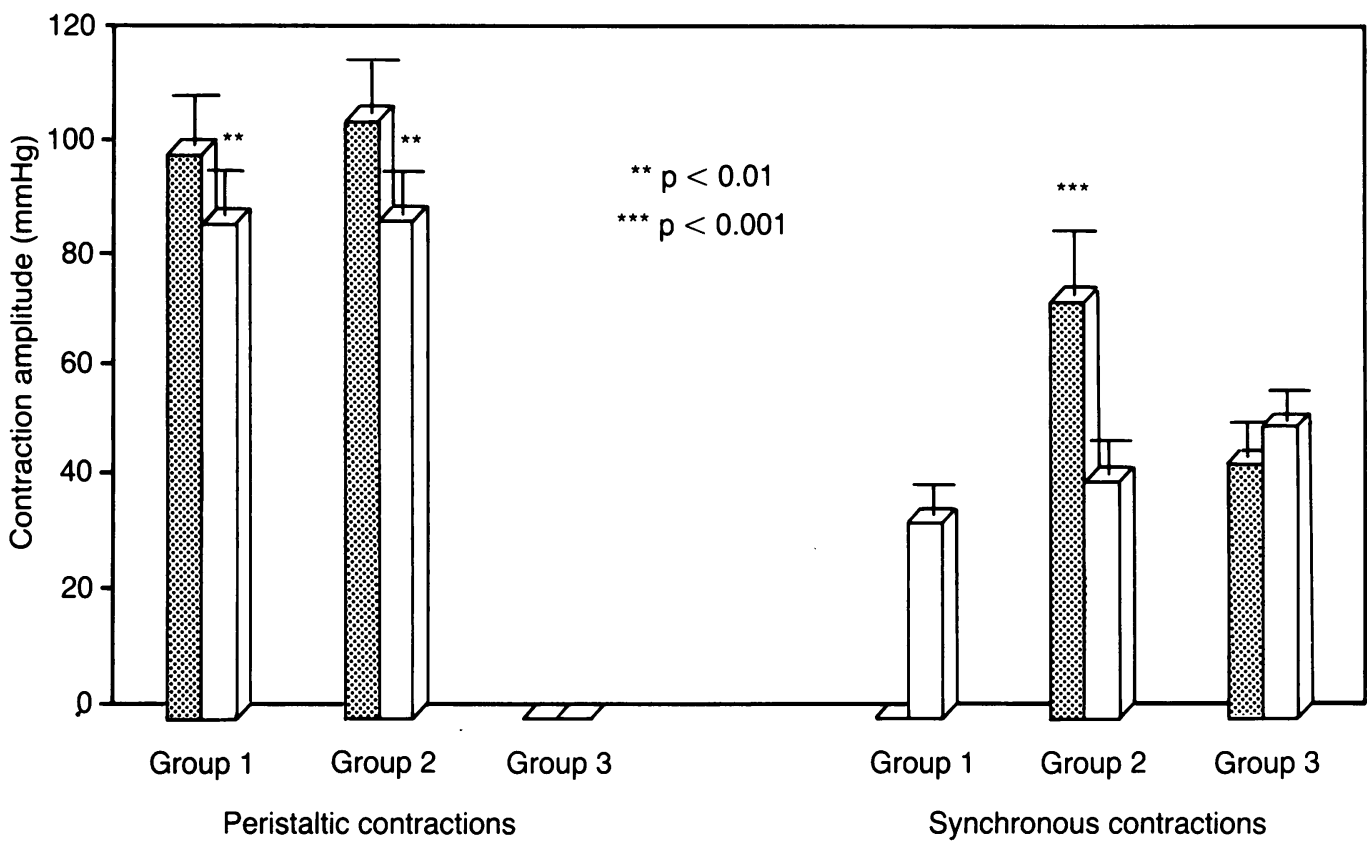

Figure 2: Amplitudes of peristaltic and synchronous contractions in response to water and bread swallows in the three groups. 

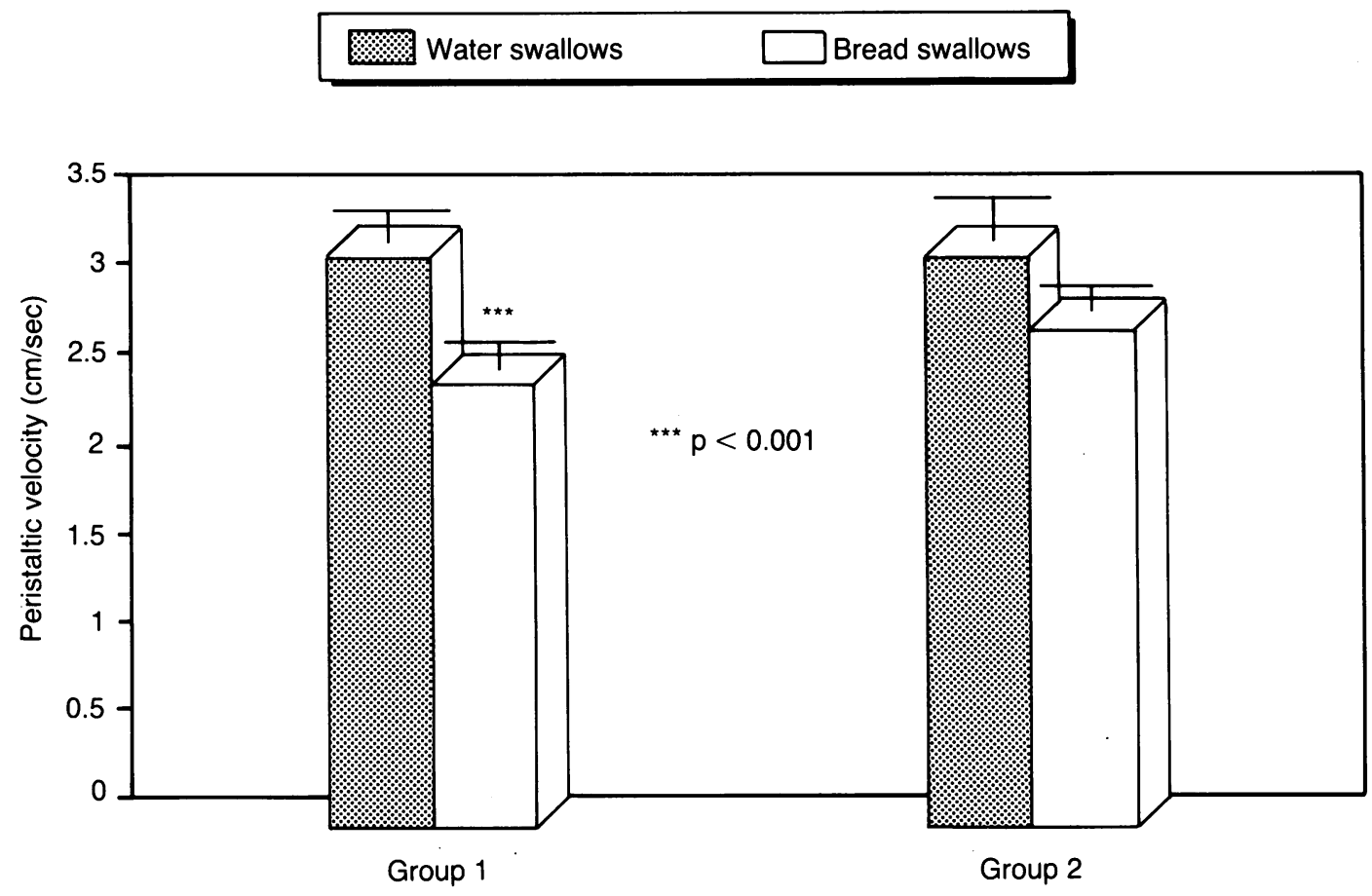

Figure 3: Peristaltic velocities with water and bread swallows in patients in groups 1 and 2.

was no significant correlation between mean synchronous contraction amplitudes with water and bread in group 2.

As Figure 3 shows; peristaltic velocities were reduced with bread compared with water swallows in group $1(2 \cdot 52(0 \cdot 13) \mathrm{cm} / \mathrm{s})$ and $3 \cdot 22$ $(0.13) \mathrm{cm} / \mathrm{s} ; \mathrm{p}<0.001)$, though not in group 2 patients $(3.09(0.86) \mathrm{cm} / \mathrm{s}$ and $3.22(0.20)$; not significant). There were, however, no significant correlations between the velocities of peristaltic contractions in response to water and bread swallows in either group 1 or 2 . There was no significant correlation between peristaltic amplitude and velocity in response to water or bread swallows in patients from group 1 . Furthermore, peristaltic velocity did not correlate with peristaltic amplitude of water swallows in group 2 patients, although there was a weak correlation between peristaltic amplitude and velocity in response to bread swallows $\left(\mathrm{r}^{2}=33.4 \% ; \mathrm{p}<0.001\right)$.

Mean (SD) swallow frequencies while eating the bread were $5.16(1.73)$ swallows/min in group 1; 5.67 (1.99) swallows/min in group 2, and $5.55(2.63)$ swallows/min in group 3 . There was a significant negative correlation between swallow frequency and the percentage of peristaltic swallows during eating in group 1 $\left(r^{2}=33.9 \% ; p<0.001\right)$ and group $2\left(r^{2}=24.8 \%\right.$; $\mathrm{p}<0.004$ ).

\section{LOWER OESOPHAGEAL SPHINCTER PRESSURE AND} RELAXATION

The median station pull through pressure in those in group 3 with achalasia was $68.0 \mathrm{~mm} \mathrm{Hg}$ (range 55-74) and was significantly greater than in patients in groups 1 and $2(39.0 \mathrm{~mm} \mathrm{Hg}$ (1761 ) and $39.6 \mathrm{~mm} \mathrm{Hg}$ (13-84) respectively; $\mathrm{p}<0.005$ ). Data on lower oesophageal relaxation in response to water and bread swallows are shown in the Table.
There were no significant differences in the degree of sphincter relaxation in response to peristaltic, synchronous, or non-conducted swallows with water in groups 1 and 2. Similarly, bread swallows produced similar degrees of relaxation irrespective of type of swallow in group 2 patients. In group 1 the degree of relaxation was significantly greater in response to peristaltic, compared with synchronous, contractions (non-conducted swallows produced similar relaxation to peristaltic swallows). In both groups 1 and 2, however, sphincter relaxation in response to peristaltic, synchronous, or nonconducted water swallows was significantly greater than with the corresponding peristaltic synchronous, or non-conducted bread swallows. As expected, sphincter relaxation was always incomplete in response to water and bread swallows in all the achalasia patients. In group 1 normal relaxation was seen in response to peristaltic water swallows in all patients. The percentages of patients with incomplete relaxation in response to peristaltic, synchronous, and nonconducted bread swallows were, however, $9 \%$, $33 \%$, and $48 \%$ respectively. In group 2 incomplete relaxation with water was found in $7 \%$ of patients in response to peristaltic contrac-

Lower oesophageal sphincter relaxation in response to water and bread swallows. Median (range) residual pressures in $\mathrm{mm}$ $\mathrm{Hg}$ above intragastric baseline

\begin{tabular}{|c|c|c|c|}
\hline Swallows & Water & Bread & Significance \\
\hline \multicolumn{4}{|l|}{ Group 1: } \\
\hline $\begin{array}{l}\text { Peristaltic } \\
\text { Synchronous }\end{array}$ & $\begin{array}{l}0(0-4 \cdot 3) \\
-\end{array}$ & $\begin{array}{l}0(0-13 \cdot 9) \\
1.9(0-17 \cdot 2)^{\star}\end{array}$ & $\underline{p}<0.05$ \\
\hline Non-conducted & - & $2 \cdot 8(0-28 \cdot 5)$ & - \\
\hline \multicolumn{4}{|l|}{ Group 2: } \\
\hline $\begin{array}{l}\text { Peristaltic } \\
\text { Synchronous }\end{array}$ & $0(0-7 \cdot 4)$ & $\begin{array}{l}1 \cdot 3(0-16 \cdot 3) \\
4 \cdot 2(0-33 \cdot 7)\end{array}$ & $\begin{array}{l}\mathrm{p}<0.005 \\
\mathrm{p}<0.005\end{array}$ \\
\hline $\begin{array}{l}\text { Non-conducted } \\
\text { Group 3: }\end{array}$ & $0(0-41 \cdot 8)$ & $4 \cdot 9(0-25 \cdot 7)$ & $\mathrm{p}<0.005$ \\
\hline $24(8-31 \cdot 9) \quad 32 \cdot 6(24 \cdot 9-35 \cdot 5) \mathrm{NS}$ & $24(8-31 \cdot 9)$ & $32 \cdot 6(24 \cdot 9-35 \cdot 5)$ & NS \\
\hline
\end{tabular}

${ }^{\star} \mathrm{p}<0.05$ compared with peristaltic bread swallows. $\mathrm{NS}=$ not significant. 
tions, 6\% with synchronous contractions and $13 \%$ with non-conducted swallows. The corresponding figures for bread swallows in group 2 were $14 \%$ for peristaltic swallows, $45 \%$ for synchronous swallows, and $45 \%$ for nonconducted swallows.

\section{Discussion}

We have recently shown that it may be useful to examine oesophageal manometry during eating in the investigation of patients with chest pain or dysphagia. $^{2}$ In a further study of 81 patients referred for diagnostic manometry and ambulatory $\mathrm{pH}$ monitoring, we found that eating provoked symptoms in almost half of the patients presenting with a history of dysphagia, many of whom had normal conventional manometry. We believe that observing oesophageal motility when patients are given solid food may allow the cause of dysphagia to be identified when it has not been identified by conventional oesophageal manometry using water swallows. This conclusion is in agreement with the studies of Mellow and coworkers who also showed that eating often produces symptoms and motility changes that are not found during conventional manometry.

Sears $e t a l^{10}$ have recently examined the effect of erect versus supine body position and liquid versus solid boluses on oesophageal motility in normal subjects. They studied isolated water or solid swallows at not less than 30 second intervals. They also examined the effect of body position on liquid swallows and compared upright liquid and solid swallows. They found that body position substantially altered normal distal oesophageal peristalsis and sphincter pressure and also that there was an increased frequency of abnormal non-peristaltic waveforms in the upright position after both solid and liquid swallows.

The aim of the present study was to make a systematic comparison of conventional oesohageal manometry with oesophageal motility during unrestrained eating in a consecutive series of unselected patients referred for oesophageal function tests. We eliminated the effects of changes in posture in our patients by performing manometry with water swallows and bread in the semirecumbent position. Clinical manometry is usually performed in this position and normal values for the various manometric parameters are already established. ${ }^{5}$ In contrast to the paper by Sears et al, neither bolus size nor swallow interval was fixed in our study as we wished to study patients while they were eating in an unrestricted way at their own pace.

Conventional manometry performed with carefully timed boluses of water had little predictive value for oesophageal motor patterns during eating. The percentage of peristaltic swallows was lower, while percentages of synchronous and non-conducted swallows were greater, during eating than with conventional manometry. There was no correlation between the percentage of peristaltic swallows during conventional manometry and during eating in either group 1 or 2. Moreover, despite the variety of manometric diagnoses in group 2, there were no significant differences in the percentages of peristaltic, synchronous, and non-conducted swallows during eating between groups 1 and 2 . Indeed, unless the patient had achalsia, it was impossible to predict the percentage of peristaltic, synchronous, and non-conducted contractions during eating from the conventional manometry with water swallows in any given patient.

Despite the importance that has been attached to a diagnosis of high amplitude peristalsis ('nutcracker oesophagus') in relation to both chest pain ${ }^{11-16}$ and dysphagia, ${ }^{16}{ }^{17}$ mean peristaltic amplitudes were actually less during eating than with water swallows. Furthermore, although periodic peristaltic 'stripping waves' were seen during eating, there was no significant difference between the maximum peristaltic amplitudes in response to water and bread swallows in groups 1 or 2. Peristaltic velocity was slower with bread swallows than with water swallows in group 1 and group 2 (though in group 2 the difference was not significant). Synchronous contractions, which were of lower amplitude than peristaltic contractions both with water and bread swallows, were less with bread than with water swallows except in patients with achalasia. Indeed, most of the patients with achalasia developed mean amplitudes in excess of $50 \mathrm{~mm} \mathrm{Hg}$ while eating, which might be thought to justify a label of 'vigorous achalasia.'

The mechanisms for the above changes are unclear, although it is known that bolus size and consistency affect peristaltic amplitude and velocity. ${ }^{1018} 19$ Swallow frequency may also affect both contraction type and peristaltic amplitude through 'deglutitive inhibition. ${ }^{20-23}$ We have previously suggested that swallow patterns may determine oesophageal motility during eating and that rapid swallowing may lead to aperistalsis and dysphagia. ${ }^{2}$ In the present study the percentage of peristaltic swallows during eating was inversely related to mean swallow frequency. With achalasia, however, and probably also with diffuse oesophageal spasm, synchronous contractions are produced at swallow intervals that would be expected to produce peristaltic contractions, which suggests that the normal 'rules' of deglutitive inhibition may not apply in these conditions.

Castell $e t a l^{24}$ have shown that a well positioned single recording orifice in the lower sphincter will give similar measurements for residual pressure to those obtained using a Dent sleeve, although the duration of sphincter relaxation was shorter with the sleeve. In their opinion, a single recording channel is the preferred technique for measuring sphincter relaxation. They found that measurement of residual pressure at the nadir of sphincter relaxation provided a more accurate assessment of relaxation than the per cent relaxation, which depends on the resting station pull through pressure, and that the duration of relaxation was related to peristaltic wave velocity. In our study we also used a single recording channel in the lower sphincter to measure residual pressure. Owing to the variable swallow intervals, however, it was not possible to measure the duration of relaxation during eating. There was pronounced interindividual variation in the extent of sphincter relaxation in response to both 
water and bread swallows in all three groups. There was no difference in the degree of sphincter relaxation in response to peristaltic, synchronous, or non-conducted water swallows. This implies that it is the act of swallowing, rather than the resultant oesophageal contractile response, that determines sphincter relaxation, at least with water swallows. Nevertheless, bread swallows consistently produced less relaxation (irrespective of the contractile response in the oesophageal body) compared with water swallows in both groups 1 and 2. It therefore seems that bolus size and consistency may modify sphincter relaxation. Unlike water swallows, peristaltic bread swallows produced a greater degree of sphincter relaxation than synchronous and non-conducted swallows in group 1 patients. Nevertheless, the overall differences in the extent of sphincter relaxation, as determined by the differences in mean residual pressures, were small and may not be of much importance physiologically when meals are eaten in the upright position and gravity can act on the food or fluid bolus.

The results confirm our previous observation that there are substantial differences in the distal oesophageal motility patterns produced by water swallows and by eating bread. These results also show that the patterns observed during conventional manometry with water swallows do not allow prediction of the patterns produced while eating the bread, except in patients with achalasia. In contrast, only small differences in lower sphincter function were apparent with the water and bread swallows.

These observations go some way to explain how patients with dysphagia for solids may have normal findings on conventional manometry. They also point to the need for careful definition of normal oesophageal motility in studies using the equipment now becoming available for ambulatory recordings. It is clear that motility patterns which would be clearly abnormal on conventional manometry are frequently observed during normal eating.

1 Allen ML, Orr WC, Mellow M, Robinson MG. Water swallows vs food ingestion as manometric tests for esophageal swallows vs food ingestion as manometric tests for
dysfunction. Gastroenterology 1988; 95: 831-3.

2 Howard PJ, Pryde A, Heading RC. Oesophageal manometry during eating in the investigation of patients with chest pain or dysphagia Gut 1989; 30: 1179-86.

3 Howard PJ, Benini L, Pryde A, Heading RC. Contribution of measurement of lower oesophageal sphincter pressure and relaxation in diagnostic oesophageal manometry. Eur $\mathcal{F}$ Gastroenterol Hepatol 1990; 2: 37-44.

4 De Caestecker JS. Twenty-four-hour oesophageal pH monitoring: advances and controversies. Neth $\mathcal{F}$ Med 1989, 34: $\$ 20-39$.

5 Richter JE, Wu WC, Johns DN. Esophageal manometry in 95 healthy adult volunteers: variability of pressure with age and frequency of 'abnormal' contractions. Dig Dis Sci 1987; 32: 583-92.

6 Vantrappen G, Clouse R, Corazziari E, Janssens J, Wienbeck $M$. A systematic approach to esophageal manometry. An outline of required measurements and technical standards. Roma88 Working Team Report 18. XIIIth International Roma88 Working Team Report 18. XIIIth Internation
Congress of Gastroenterology. Rome: Mediamed, 1988.

7 Vantrappen G, Hellemans J. Studies of the normal deglutitive complex. Am F Dig Dis 1967; 12: 232-5

8 Benjamin SB, Richter JE, Cordova CM, Knuff TE, Castell DO. Prospective manometric evaluation with pharmacologic provocation of patients with suspected esophageal motility dysfunction. Gastroenterology 1983; 84: 893-901.

9 Howard PJ, Maher L, Pryde A, Heading RC. Oesophagea motility during episodes of dysphagia for solids. Gut 1990 31: A594.

10 Sears VW, Castell JA, Castell DO. Comparison of effects of upright versus supine body position and liquid versus solid bolus on esophageal pressure in normal humans. Dig Dis $S_{c i}$ 1990; 35: 857-64.

11 De Caestecker JS, Blackwell JN, Brown J, Heading RC. The oesophagus as a cause of recurrent chest pain: which patients should be investigated and which tests should be used? Lancet 1985; ii: 1143-6.

12 Brand DL, Martin D, Pope II CE. Esophageal manometries in patients with angina-like chest pain. Dig Dis Sci 1977; 2 $300-4$.

13 Alban Davies H, Kaye MD, Rhodes J, Dart AM, Henderson AH. Diagnosis of oesophageal spasm by ergometrine provocation. Gut 1982; 23: 89-97.

14 Clouse RE, Staiano A, Landau DW, Schlachter JL. Manometric findings during spontaneous chest pain in patients with presumed esophageal 'spasms'. Gastroenterology 1983; 85: $395-402$.

15 London RL, Ouyang A, Snape WJ, Goldberg S, Hirshfeld JW, Cohen S. Provocation of esophageal pain by ergonovine or edrophonium. Gastroenterology 1981;81: 10-4.

16 Benjamin SB, Gerhardt DC, Castell DO. High amplitude peristaltic esophageal contractions associated with chest pain and/or dysphagia. Gastroenterology 1979; 77: 478-83.

17 Mellow MH. Esophageal motility during food ingestion: a physiologic test of esophageal motor function. Gastroenterology 1983; 85: 570-7.

18 Dodds WJ, Hogan WJ, Reid DP, Stewart ET, Arndorfer RC. A comparison between primary esophageal peristalsis following wet and dry swallows. F Appl Physiol 1973; 35: 851-7.

19 Hollis JB, Castell DO. Effect of dry and wet swallows of different volumes on esophageal peristalsis. $\mathcal{F}$ Appl Physiol different volumes

20 Vanek AW, Diamant NE. Responses of the human esophagus to paired swallows. Gastroenterology 1987; 92: 643-50.

21 Hellemans J, Vantrappen G, Janssens J. Electromyopathy of the esophagus. 4. The deglutitive inhibition. In: Vantrappen G, Hellemans J, eds. Diseases of the esophagus. New York: Springer-Verlag, 1974; $280-4$

22 Meyer GW, Gerhardt DC, Castell DO. Human esophageal response to rapid swallowing: muscle refractory period or neural inhibition? Am $\mathcal{F}$ Physiol 1981; 241: G129-36.

23 Ask $P$, Tibbling $L$. Effect of time interval between swallows on esophageal peristalsis. Am $\mathcal{F}$ Physiol 1980; 238; G485-90.

24 Castell JA, Dalton CB, Castell DO. on-line computer analysis of human lower oesophageal sphincter relaxation. Am $\mathcal{J}$ Physiol 1988; 255: G794-9. 